\title{
Determination of in vitro isoflavone degradation in rumen fluid
}

\author{
Andrea Trnková, ${ }^{*}$ Kateřina Šancová, ${ }^{*}$ Martina Zapletalová, ${ }^{*}$ Jitka Kašparovská, ${ }^{*}$ Kateřina Dadáková, ${ }^{*}$ \\ Ludmila Kř́žžová, ${ }^{*}$ Jan Lochman, ${ }^{*}$ Sylvie Hadrová, ${ }^{*}$ Ivana Ihnatová,† and Tomáš Kašparovský*1 \\ *Department of Biochemistry, Faculty of Science, and \\ †Research Centre for Toxic Compounds in the Environment, Faculty of Science, Masaryk University, Kotlarska 2, 61137 Brno, Czech Republic
}

\begin{abstract}
The aim of this study was to determine the degradation of dietary isoflavones in rumen fluid under 2 feeding regimens. The experiments were performed in vitro using a rumen fluid buffer system. The rumen fluid was taken from cows fed either a hay diet or a concentrate-rich diet (the diet consisted of $34.6 \%$ maize silage, $17.6 \%$ haylage, $12.8 \%$ alfalfa hay, and $35.0 \%$ supplemental mixture on a dry matter basis). As a source of isoflavones, $40 \%$ soybean extract (Biomedica, Prague, Czech Republic) at levels of 5, 25, 50, and 75 $\mathrm{mg}$ per $40 \mathrm{~mL}$ of rumen fluid was used. Samples of soybean extract were incubated in triplicate at $39^{\circ} \mathrm{C}$ for $0,3.0,6.0,12.0$, and $24.0 \mathrm{~h}$ in incubation solution. The metabolism of daidzein and genistein was faster under concentrate-rich diet conditions. In general, production of equol started after 3 to $6 \mathrm{~h}$ of incubation and reached the highest rate after approximately $12 \mathrm{~h}$ of incubation regardless of the type of diet or concentration of extract. In most of the experiments, production of equol continued after $24 \mathrm{~h}$ of incubation. Generally, equol production was greater under the hay diet conditions. Furthermore, experiments with higher amounts of added soybean extract revealed possible inhibitory effects of high levels of isoflavones on the rumen microflora.
\end{abstract}

Key words: isoflavones, equol, rumen, cattle diet

\section{INTRODUCTION}

Ruminant feedstuffs may contain isoflavones, which are known to have weak estrogenic activity (Zhengkang et al., 2006). Two major sources of isoflavones are commonly used in the nutrition of dairy cows: soy (Glycine max) and red clover (Trifolium pratense L.). Soybeans and soybean products-common components

Received July 31, 2017.

Accepted January 26, 2018.

${ }^{1}$ Corresponding author: tkasp@sci.muni.cz of dairy cattle diets (Chouinard et al., 1997) - are rich in the isoflavones genistein and daidzein (Chan et al., 2009), but these can be further metabolized by microorganisms in the gastrointestinal tract to more potent metabolites (Schoefer et al., 2002; Wang et al., 2005; Wocławek-Potocka et al., 2013). In the rumen, daidzein is further metabolized to equol and genistein is metabolized to p-ethyl-phenol (Lundh et al., 1990; Lundh, 1995). Although $p$-ethyl-phenol is an inactive metabolite (Setchell et al., 2002), equol is more bioactive than its precursor daidzein, with higher estrogenicity (Kostelac et al., 2003), antioxidant activity (Turner at al., 2004), and antiandrogenic properties (Lund et al., 2004).

The rumen is a phylogenetically complex ecosystem, where microorganisms convert feedstuffs into microbial biomass and fermentation end products that can be utilized by the host animal (Kong et al., 2010). Three taxonomic groups of microorganisms - bacteria, protozoa, and fungi-carry out this digestion process in the rumen. Edwards et al. (2004) suggested that the rumen might contain 300 to 400 bacterial species. This microbiota is highly responsive to many factors, especially to changes in the feeding regimen and in the composition of the diet, to the health of the host animal, or to antibiotic use (e.g., Hungate, 1966; Stewart and Bryant, 1988; Tajima et al., 2000, 2001).

The adaptation of the rumen to a high-grain diet principally involves increases in the populations of bacteria capable of utilizing lactic acid (Counotte and Prins, 1981). Using quantitative PCR, Tajima et al. (2000, 2001) detected gram-positive bacteria belonging to the Selenomonas-Succiniclasticum-Megasphaera group with Selenomonas ruminantium and Megasphaera multiacida being the most numerous group in the grain diet microbiota. Furthermore, they found that numbers of $R u$ minococcus flavefaciens and Fibrobacter succinogenes in animals on a hay diet were up to 20 times higher than those of animals for which the diet was switched from hay to grain, and concluded that the dynamics of the truly fibrolytic rumen bacteria correlated strongly with the diet change (Tajima et al., 2001). Such changes in 
the profile of rumen microbiota may affect the metabolism of certain substances in the rumen.

Recent studies suggest that isoflavones may have beneficial (Zhu et al., 2002; Mao et al., 2007) or inhibitory (Verdrengh et al., 2004; Mukne et al., 2011) effects on rumen microorganisms. Conversely, the effect of diet on the metabolism of isoflavones has been documented in some studies. Gagnon et al. (2009) and Petit et al. (2009) observed that PUFA affected bacteria with $\beta$-glucuronidase activity such as Ruminococcus, Bacteroides, Bifidobacterium, and Eubacterium, which may be involved in deconjugation of isoflavone glycosides. Furthermore, the level of conversion of daidzein to equol can be influenced by feed intake (Njåstad et al., 2014) or by intake of some nutrients such as nonstarch polysaccharides (Ohta et al., 2002; Lipovac et al., 2015), fat (Rowland et al., 2000), fiber, or a higher proportion of plant proteins (Lampe et al., 1998; Nielsen and Williamson, 2007).

Thus, the aim of the study was to determine the effect of type of diet and concentration of dietary isoflavones on their metabolism in the rumen using in vitro methods.

\section{MATERIALS AND METHODS}

\section{Experimental Design, Animals, and Diets}

The experiments were performed in vitro using a rumen fluid buffer system. As a natural source of isoflavones, $40 \%$ soybean extract (Biomedica, Prague, Czech Republic) in powder form was used, which contained daidzein, genistein, and glycitein in the ratio 1:0.070:0.003. In the whole experiment, 4 amounts of soybean extract, $5,25,50$, and $75 \mathrm{mg}$ per $40 \mathrm{~mL}$ of the buffered rumen fluid, were used to investigate the kinetics of isoflavone degradation. As a source of rumen fluid, nonlactating cows fed a hay diet or lactating dairy cows fed a concentrate-rich diet were used. The concentraterich diet consisted of $34.6 \%$ maize silage, $17.6 \%$ haylage, $12.8 \%$ alfalfa hay, and $35.0 \%$ supplemental mixture (on a DM basis). The supplemental diet contained $(\mathrm{g} / \mathrm{kg})$ : barley 266.0; oat 266.0; sugarbeet chippings 150.0; extruded rapeseed meal 282.2; rapeseed oil 10.5; sodium chloride 5.5; dicalcium phosphate 7.5; limestone 10.5; sodium bicarbonate 1.0; blend-s minerals 0.5 (Biokron s.r.o., Blučina, Czech Republic); and blend-s vitamins 0.5 (Biokron s.r.o.). Animal handling was performed according to current Czech legislation (Act No. 246/1992 Coll. to protect animals against cruelty, as amended). Rumen fluid was collected $3 \mathrm{~h}$ after morning feeding via rumen cannula (2 dry rumen-cannulated cows) or via a flexible, stainless-steel stomach tube (2 intact lactating cows), placed in bottles with $\mathrm{CO}_{2}$, and transferred to the laboratory in a heat-stable box. Immediately, $\mathrm{pH}$ was measured and the rumen fluid from the 2 cows on the same diet was mixed and filtered through 4 layers of cheesecloth. The fluid was then mixed with a prewarmed buffer $\left(39^{\circ} \mathrm{C}\right)$ in a ratio of $1: 1$. The buffer (pH 6.9) was composed of solutions A and B (A:B 5:1) with following compositions: solution $\mathrm{A}=10.0 \mathrm{~g} / \mathrm{L}$ $\mathrm{KH}_{2} \mathrm{PO}_{4}, 0.5 \mathrm{~g} / \mathrm{L} \mathrm{MgSO}_{4} \cdot 7 \mathrm{H}_{2} \mathrm{O}, 0.5 \mathrm{~g} / \mathrm{L} \mathrm{NaCl}, 0.1 \mathrm{~g} / \mathrm{L}$ $\mathrm{CaCl}_{2} \cdot 2 \mathrm{H}_{2} \mathrm{O}$, and $0.5 \mathrm{~g} / \mathrm{L}$ urea; solution $\mathrm{B}=15.0 \mathrm{~g} / \mathrm{L}$ $\mathrm{Na}_{2} \mathrm{CO}_{3}$ and $1.0 \mathrm{~g} / \mathrm{L} \mathrm{Na} 2 \mathrm{~S} \cdot 9 \mathrm{H}_{2} \mathrm{O}$.

The incubation process was conducted in $90-\mathrm{mL}$ (thick-walled) glass tubes containing $40 \mathrm{~mL}$ of incubation solution, $0.5 \mathrm{~g}$ of the respective diet (hay or concentrate-rich) ground through a 1-mm screen, and soybean extract at 4 levels as noted above, with each level in triplicate. Tubes were purged with $\mathrm{CO}_{2}$ before being sealed with rubber stoppers with a Bunsen gas release valve. Then, samples were incubated at $39^{\circ} \mathrm{C}$ for $0,3.0,6.0,12.0$, and $24.0 \mathrm{~h}$ with gentle manual shaking 3 times per day. For each type of diet, in vitro incubations were conducted one at a time.

\section{Sample Preparation}

The samples were taken after $0,3.0,6.0,12.0$, and $24.0 \mathrm{~h}$ of incubation from separate tubes so that only one sampling was done from each tube. Collected samples were cooled in ice water, centrifuged to separate off the microbial mass $\left(5,000 \times g, 15 \mathrm{~min}, 5^{\circ} \mathrm{C}\right)$, and kept frozen at $-20^{\circ} \mathrm{C}$ until analyses. Each run was done 3 times. Fermented samples were analyzed for the content of isoflavones (daidzein, glycitein, genistein) and the metabolite equol.

Sample preparation was done according to the method described in our previous paper (Kasparovska et al., 2016a) with the following modifications. The sample of rumen fluid was extracted twice to ethyl acetate and evaporated to dryness. The residue was thoroughly dissolved in $1 \mathrm{~mL}$ of water and the acids were removed from the sample by solid-phase extraction (Chromabond SB, Macherey Nagel, Düren, Germany). The samples were evaporated to dryness, dissolved in $1 \mathrm{~mL}$ of $50 \%$ methanol, and filtered through a $0.20-\mu \mathrm{m}$ filter.

\section{Analytical Procedure}

The soybean extract added to the reactions contained primarily daidzein, genistein, and glycitein. First, we analyzed a part of the samples using liquid chromatography-mass spectrometry (LC-MS) to screen for analytes. These analyses found no glycosylated 
isoflavones. Based on these results, we introduced an HPLC method to monitor the concentrations of daidzein, glycitein, genistein, and equol. We used this method to analyze the rest of the samples.

The LC-MS analyses were performed according to the method described in our previous paper (Kasparovska et al., 2016a). The HPLC analyses were carried out on an Ascentis Express C18 column $(15 \mathrm{~cm} \times 4.6 \mathrm{~mm}$, $2.7 \mu \mathrm{m}$; Supelco, Bellefonte, PA). The HPLC mobile phases were (A) $0.1 \%$ acetic acid in water, and (B) methanol. Gradient conditions were 40 to $70 \%$ B from 0 to $10 \mathrm{~min}, 70$ to $100 \% \mathrm{~B}$ from 10 to $10.1 \mathrm{~min}$, and $100 \%$ B from 10.1 to $23 \mathrm{~min}$, at a flow rate of $0.7 \mathrm{~mL} /$ min and injection volume of $5 \mu \mathrm{L}$. Daidzein, genistein, and glycitein were detected by absorption $(260 \mathrm{~nm})$ and equol was detected by fluorescence with excitation and emission wavelengths of 280 and $320 \mathrm{~nm}$, respectively.

\section{Statistical Analysis}

Amounts of added soybean extract and incubation time were transformed into categorical variables before statistical analysis. The concentration of studied compounds was first compared between diet types by Mann-Whitney test and between amounts of soybean extracts and incubation time points by Kruskal-Wallis test.

Then, a generalized linear model with gamma distribution and inverse link function was fitted to concentration of each studied chemical compound. The model included main effects of diet, added soybean extract, and incubation time, as well as all pairwise interactions, as follows:

$$
\begin{aligned}
\frac{1}{\mu_{i j k}} & =\mu_{0}+\text { Diet }_{i}+\text { Extract }_{j}+\text { Time }_{k}+\text { Diet }_{i} \times \text { Extract }_{j} \\
& + \text { Diet }_{i} \times \text { Time }_{k}+\text { Extract }_{j} \times \text { Time }_{k},
\end{aligned}
$$

where $\mu_{i j k}$ is mean concentration for $i$ th diet, $j$ th added level of soybean extract, and $k$ th incubation time; $\mu_{0}$ denotes initial reciprocal mean concentration for hay diet with $5 \mathrm{mg}$ of added soybean extract; Diet $_{i}$ denotes effect of ith diet; Extract ${ }_{j}$ denotes effect of $j$ th level of added soybean extract; Time $_{k}$ denotes effect of $k$ th incubation time; and $\times$ denotes interaction of 2 factors. Effect of the diet type, level of added soybean extract, and incubation time were assessed via relevant contrasts evaluated by the Wald test. The statistical analysis was performed in R (https://www.r-project .org/) using packages stats and contrast. The threshold for statistical significance was set to $5 \%$.

\section{RESULTS}

\section{Effect of Diet Type}

Isoflavone Degradation. The concentrations of daidzein and genistein combined across amount of soybean extract and incubation time were significantly different between diet types $(P=0.019$ and $P=0.022$, respectively) but the concentration of glycitein did not differ $(P=0.455)$. Estimated mean concentrations and boundaries of $95 \%$ CI of the individual compounds for each combination of the diet type, levels of added soybean extract, and incubation times are shown in Supplemental Table S1 (https://doi.org/10.3168/jds .2017-13610). Median concentrations of daidzein and genistein were higher in incubations based on the hay diet than on the concentrate-rich diet (Figure 1). The kinetics of isoflavone degradation for individual diet types, added soybean extract amounts, and incubation times are shown in Figure 2. Concentrations of each isoflavone decreased monotonously with increasing incubation time for both diets and all amounts of added soybean extract except for the hay diet with 75 $\mathrm{mg}$ of soybean extract, where isoflavone concentrations increased after $3 \mathrm{~h}$ of incubation. A statistically significant effect of the diet type was identified only for daidzein and genistein. The concentration of daidzein was different after $3 \mathrm{~h}$ of incubation with $50 \mathrm{mg}$ of added soybean extract and after 6 and $12 \mathrm{~h}$ of incubation with $>5 \mathrm{mg}$ of added soybean extract $(P<0.005)$. The estimated concentration of genistein differed between the 2 diets for all levels of added soybean extract and incubation times of 6 and $12 \mathrm{~h}$ and for a 3 -h incubation with $25 \mathrm{mg}$ of added soybean extract $(P<0.005)$.

Equol Production. The concentrations of equol combined across amounts of soybean extract and incubation times were significantly different between diet types $(P=0.037)$. The median concentration of equol was higher in the incubations based on hay than in those based on the concentrate-rich diet (Figure 1). Equol production was also higher in the incubations based on hay in individual levels of added soybean extract and incubation time. With the lowest added amount of soybean extract $(5 \mathrm{mg})$, the equol concentration reached a plateau after $12 \mathrm{~h}$ of incubation under the hay diet. The highest concentration of equol was observed for the hay diet after $24 \mathrm{~h}$ of incubation with $25 \mathrm{mg}$ of soybean extract. With higher amounts of soybean extract (50 or $75 \mathrm{mg}$ ), the effect of the diet type was less prominent. The effect of diet type was statistically significant for 6 and $12 \mathrm{~h}$ of incubation after adding any of the studied amounts of soybean extract and for the 24-h incubation 

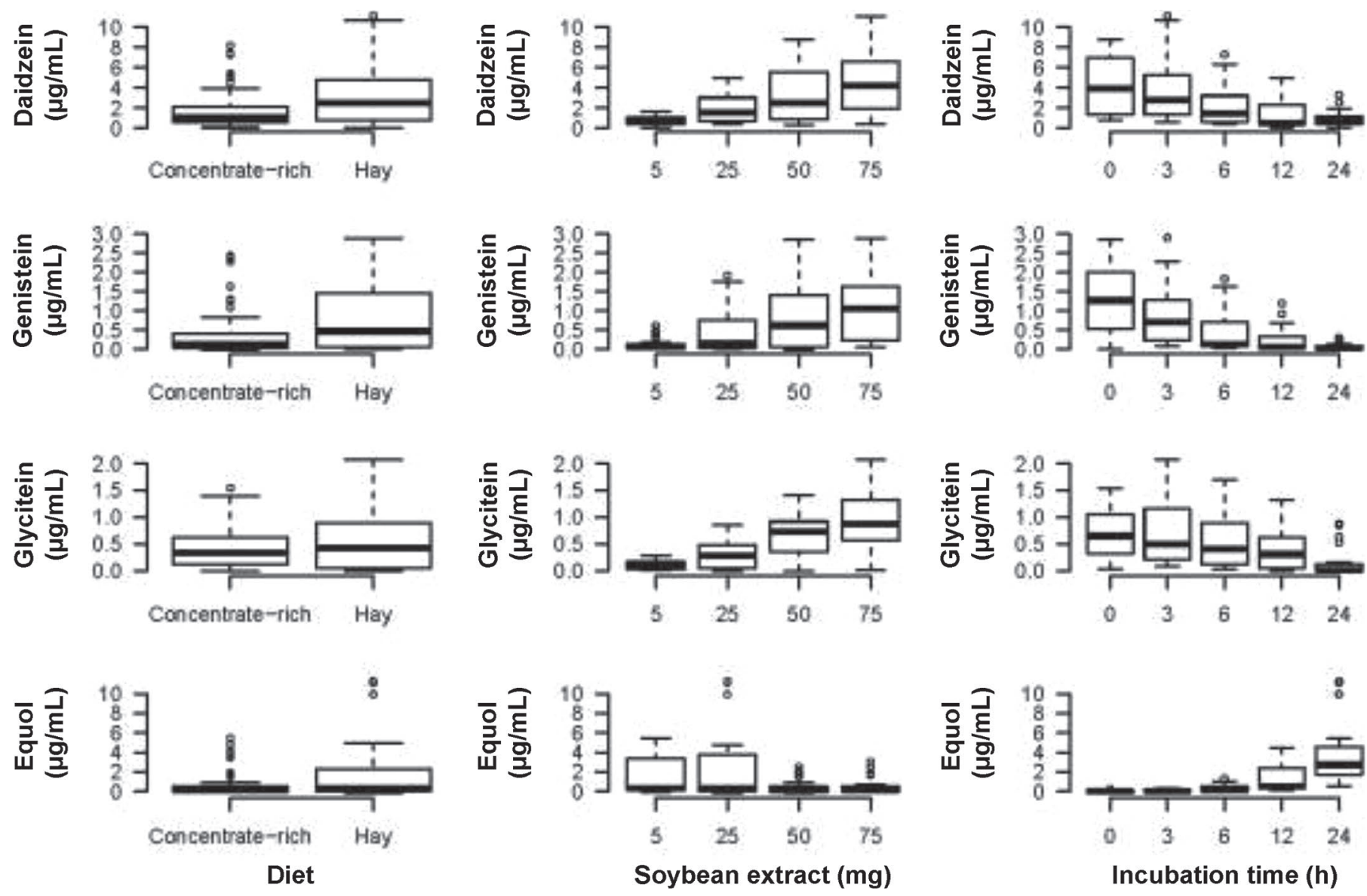

Figure 1. Distribution of concentrations of compounds divided by individual factors (diet type, added soybean extract, and incubation time). Boxplots display medians (solid line inside box), first and third quartiles (box), and extreme and outlying values (whiskers and open circles).

with the highest added amount of soybean extract $(75$ mg; $P<0.005)$.

\section{Effect of Level of Added Soybean Extract}

Isoflavone Degradation. The concentrations of all isoflavones combined across the diet type and incubation time were significantly different among the levels of added soybean extract $(P<0.001$ for all $)$. Isoflavone concentrations increased with increasing levels of added soybean extract (Figure 1). Generally, initial isoflavone concentrations increased with the increasing amount of added soybean extract. The estimated initial concentration of daidzein for $5 \mathrm{mg}$ of soybean extract was 0.91 and $1.22 \mu \mathrm{g} / \mathrm{mL}$ for hay and concentrate-rich diets, respectively, and for $75 \mathrm{mg}$ of soybean extract was 6.60 and $7.02 \mu \mathrm{g} / \mathrm{mL}$ for hay and concentrate-rich diets, respectively. The highest initial concentration was estimated for the hay diet and $50 \mathrm{mg}$ of added soybean extract $(8.21 \mu \mathrm{g} / \mathrm{mL})$. In concordance with the ratio of isoflavone concentrations in the soybean extract, the initial concentrations of genistein and glycitein were lower than that of daidzein. For genistein, we estimated the mean concentration to range from $0.31 \mu \mathrm{g} / \mathrm{mL}$ (concentrate-rich diet and $5 \mathrm{mg}$ of added soybean extract) to $2.48 \mu \mathrm{g} / \mathrm{mL}$ (hay diet and $50 \mathrm{mg}$ of added soybean extract). For glycitein, we estimated the mean concentration to range from $0.15 \mu \mathrm{g} / \mathrm{mL}$ (hay diet and $5 \mathrm{mg}$ of added soybean extract) to $1.29 \mu \mathrm{g} /$ $\mathrm{mL}$ (hay diet and $75 \mathrm{mg}$ of added soybean extract). The final concentration of isoflavones was the lowest for $5 \mathrm{mg}$ of added soybean extract (from $0.02 \mu \mathrm{g} / \mathrm{mL}$ for genistein and concentrate-rich diet to $0.37 \mu \mathrm{g} / \mathrm{mL}$ for daidzein and the same diet type) and the highest for $75 \mathrm{mg}$ of added soybean extract (from $0.14 \mu \mathrm{g} / \mathrm{mL}$ for genistein and concentrate-rich diet to $2.00 \mu \mathrm{g} / \mathrm{mL}$ for daidzein and the hay diet).

Equol Production. The concentrations of equol combined across the diet type and incubation time were not significantly different between levels of added 


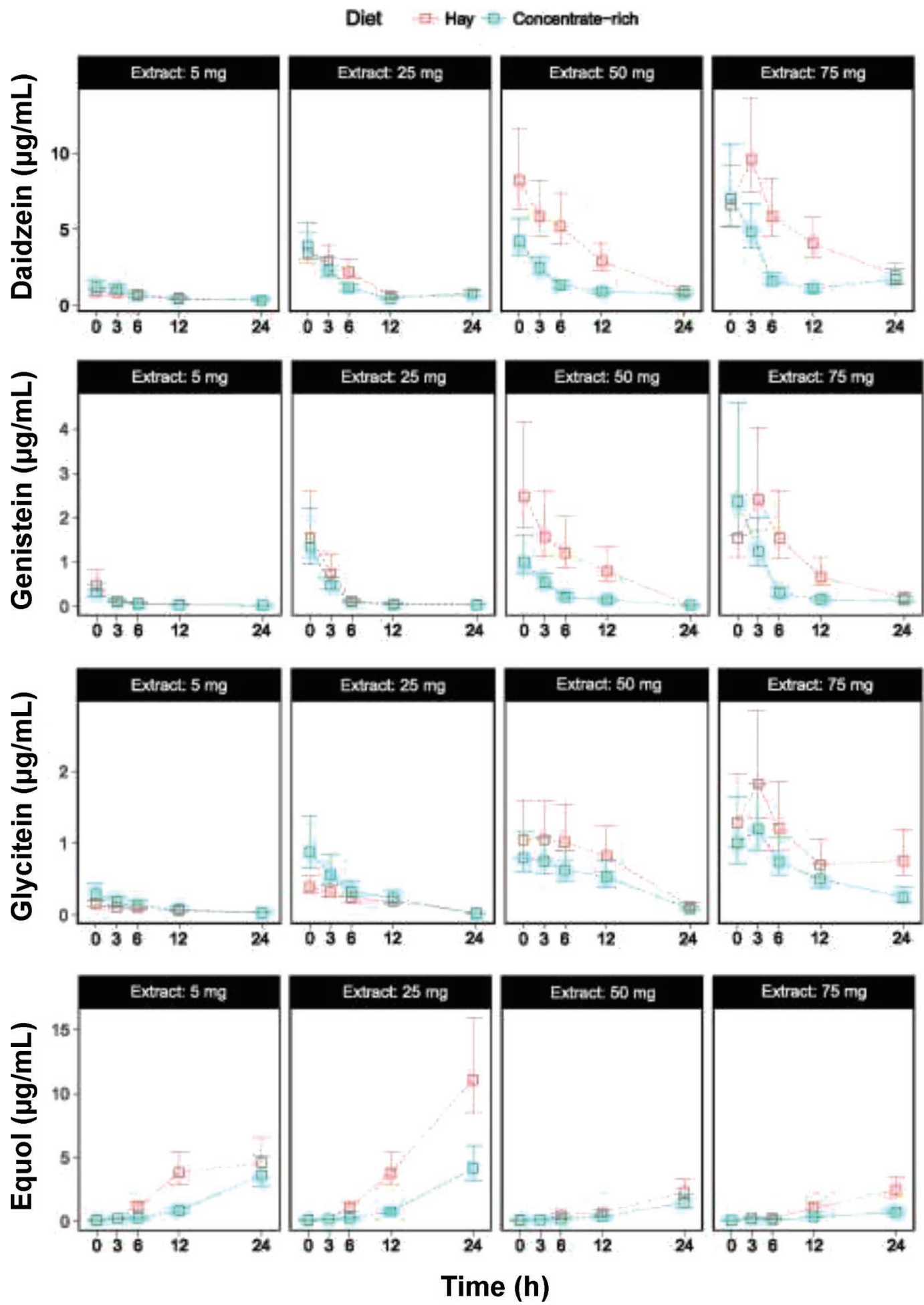

Figure 2. Estimated mean concentration of individual compounds (squares or diamonds connected by dashed line) and their standard errors for different diets, levels of added soybean extract $(5,25,50$, or $75 \mathrm{mg})$, and incubation times. Color version available online.

soybean extract $(P=0.149)$. The estimated initial concentration of equol was between 0.08 and $0.12 \mu \mathrm{g} /$ $\mathrm{mL}$ and similar between diet types and levels of added soybean extract. In contrast, concentrations of equol after $24 \mathrm{~h}$ of incubation were highest with $25 \mathrm{mg}$ of added soybean extract (11.11 and $4.16 \mu \mathrm{g} / \mathrm{mL}$ for hay 
and concentrate-rich diet, respectively) and lowest with $75 \mathrm{mg}$ of added soybean extract $(2.46$ and $0.73 \mu \mathrm{g} / \mathrm{mL}$ for hay and concentrate-rich diet, respectively).

\section{Effect of Incubation Time}

Isoflavone Degradation. The concentrations of all isoflavones combined across diet type and levels of added soybean extract were significantly different between incubation times $(P<0.001$ for all compounds). The concentrations of daidzein, genistein, and glycitein decreased during the time-course of the incubations (Figure 1). The estimated mean initial isoflavone concentrations were higher than the final concentrations for each level of added soybean extract and diet type (Figure 3). However, a statistically significant difference was observed only for daidzein with the concentraterich diet after adding $75 \mathrm{mg}$ of soybean extract and for genistein with hay diet and $50 \mathrm{mg}$ of soybean extract and for both diets with $75 \mathrm{mg}$ of soybean extract $(P<$ $0.005)$.

Equol Production. The concentration of equol combined across diet type and levels of added soybean extract were significantly different between incubation times $(P<0.001)$. It increased with increasing incubation time (Figure 1). The estimated final equol concentrations were higher than the initial concentrations for each level of added soybean extract in both diet types. The highest equol concentration was observed for 24 $\mathrm{h}$ of incubation based on the hay diet with $25 \mathrm{mg}$ of soybean extract. The kinetics of equol production are shown in Figure 2. In incubations based on the concentrate-rich diet, equol production started after about 6 $h$ and continued until the end of the experiment, after $24 \mathrm{~h}$ of incubation. In the incubation based on the hay diet, the kinetics of equol production differed between incubations with different amounts of added soybean extract. When we added $5 \mathrm{mg}$ of soybean extract, equol production began after about $3 \mathrm{~h}$ of incubation and reached a plateau after $12 \mathrm{~h}$ of incubation. With $25 \mathrm{mg}$ of added soybean extract, production of equol started after $3 \mathrm{~h}$ of incubation and continued after $24 \mathrm{~h}$ of incubation. With higher amounts of added soybean extract (50 or $75 \mathrm{mg}$ ), the kinetics of equol production resembled that observed in the incubations based on the concentrate-rich diet.

\section{DISCUSSION}

\section{Initial Isoflavone Concentrations}

In all cases, the measured concentrations of isoflavones, even at the beginning of the experiments, were substantially lower than the expected concentrations based on the amounts present in the soybean extract. Poor solubility of isoflavones in water and other nonpolar solvents (Nan et al., 2014), which ranges from 0.8 to $4 \mu \mathrm{g} / \mathrm{mL}$ (Stancanelli et al., 2007; Xu and Luo, 2014), could explain this discrepancy, because we discarded excess amounts of undissolved isoflavones by centrifugation during sample processing. However, solubility is positively influenced by temperature and differs in different solvents (Nan et al., 2014). We observed greater solubility of daidzein $(9.5 \mu \mathrm{g} / \mathrm{mL})$ in samples of rumen fluid incubated with $75 \mathrm{mg}$ of soybean extract. Recent studies (Deng et al., 2016, 2017) proved that solubility of daidzein could be improved by complexation with some cyclodextrin derivatives (cyclic oligosaccharides usually produced from starch in the presence of cyclodextrin glucosyl transferase). Park et al. (2013) found, in their experiment on mice, that daidzein had inhibitory effects against $\alpha$-glucosidase and $\alpha$-amylase, enzymes involved in metabolism of polysaccharides, and that these inhibitory effects were dose-dependent. These 2 factors could explain our findings.

The disappearance of isoflavones could have resulted from their rapid metabolism to compounds that were not detectable by the methods used in this study, as suggested by Rafii et al. (2012) and Gardana et al. (2009). However, our preliminary results obtained with autoclaved rumen fluid suggest that this was not the case (data not shown).

\section{Isoflavone Metabolism}

Generally, isoflavones were metabolized and their concentrations decreased during the in vitro cultivations. We monitored equol because it is the most important metabolite in terms of human health. The production of equol began after about $3 \mathrm{~h}$ of incubation and reached the highest rate of production after approximately $12 \mathrm{~h}$ of incubation. Production of equol continued after $24 \mathrm{~h}$ of incubation, unless the daidzein concentration decreased below $0.5 \mu \mathrm{g} / \mathrm{mL}$. Our results are in agreement with an early study of Dickinson et al. (1988), who showed, in their in vitro study with incubation of formononetin and biochanin $\mathrm{A}$ in bovine rumen fluid, that the half-life of daidzein was $9.3 \mathrm{~h}$ and that of genistein was $5.5 \mathrm{~h}$. Recently, Elghali et al. (2012) detected equol $6 \mathrm{~h}$ following addition of daidzein to medium with a single culture of 2 Bifidobacterium strains. Furthermore, they noted that the ability of Bifidobacterium strains to transform daidzein to equol increased greatly over time, although the amount of equol produced by the different Bifidobacterium strains differed. The equol levels increased during the incu- 

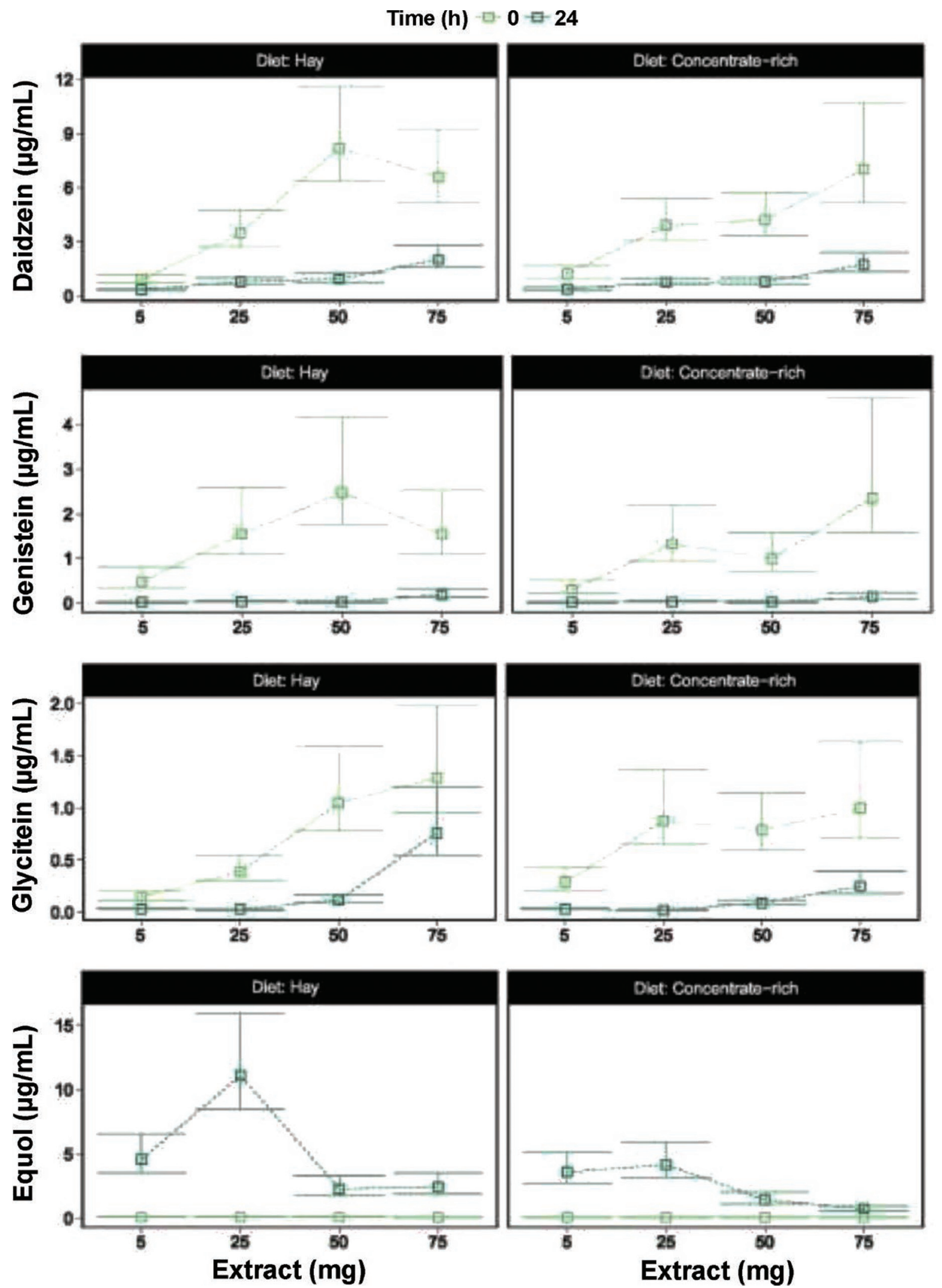

Figure 3. Estimated initial $(\nabla, 0 \mathrm{~h})$ and final $(\triangle, 24 \mathrm{~h})$ mean concentration of individual compounds (triangles connected by dashed lines) and their standard errors for different diets and levels of added soybean extract. Color version available online. 
bation period, indicating that equol was stable in the medium and was not converted to other metabolites.

The effect of diet on metabolism of isoflavones in the rumen is not clear because many factors can be involved in this process. Faster degradation of daidzein and genistein observed in the incubations based on the concentrate-rich diet could be attributed to an improvement in isoflavone solubility after their complexation with products of starch metabolism, as suggested by Deng et al. (2016, 2017). In turn, this degradation of isoflavones may result in their decreased availability, as described Lipovac et al. (2015), resulting in lower equol production in the concentrate-rich diet compared with the hay diet. Furthermore, other nutrients such as fiber (Lampe et al., 1998) or fat (Rowland et al., 2000) may affect the conversion of daidzein to equol; however, some studies suggest that production of equol is positively correlated not only with total fat intake but also the fat:fiber ratio (Lampe et al., 1998; Rowland et al., 2000) and negatively correlated with the content of PUFA (Petit et al., 2009). Based on these findings, more favorable conditions in our study for conversion of daidzein to equol occurred in incubations based on the hay diet, where higher equol production was observed, than in the concentrate-rich diet. Further studies are needed to clarify the effect of diet on isoflavone metabolism in ruminants.

\section{Inhibition of Equol-Producing Bacteria}

Our results showed that higher amounts of added soybean extract led to decreased equol production, probably due to inhibition of equol-producing bacteria. Isoflavones have been shown to possess antimicrobial activities mainly against gram-positive bacteria such as Clostridium and Streptococcus spp. (Flythe and Kagan, 2010; Flythe et al., 2013; Hummelova et al., 2015). Inhibition of gram-negative bacteria is low and seems to be species-dependent (Verdrengh et al., 2004; Mukne et al., 2011). Based on human and animal studies, several candidate gram-positive bacteria-Clostridium spp., Eubacterium spp., Bifidobacterium spp., Ruminococcus spp., and Streptococcus spp.-may play a role in the rumen metabolism of daidzein to equol and it is evident that different bacteria are involved in different stages of the biotransformation of daidzein to equol (Hur et al., 2000, 2002; Schoefer et al., 2002; Tsangalis et al., 2002; Blaut et al., 2003; Yuan et al., 2007; Gaya et al., 2016).

Inhibitory properties of individual isoflavones differ. More pronounced effects on bacterial growth have been reported for genistein than for daidzein (Verdrengh et al., 2004). Further, biochanin A, which is converted to genistein in the rumen, shows antibacterial properties (Harlow et al., 2017a).

Two bacterial type II topoisomerases have been identified: topoisomerase IV and gyrase, and they are targets for broad-spectrum antibiotics (Heisig, 2001). Genistein is a topoisomerase II inhibitor (Bernard et al., 1997; Mukne et al., 2011), whereas daidzein has been shown not to induce DNA strand breaks in cultured cells (Kulling and Metzler, 1997). In addition, genistein acts as a protein tyrosine kinase inhibitor (Morris et al., 1999) and may exert antibacterial activities by modulating the methylation patterns of the bacterial DNA (Day et al., 2002; Verdrengh et al., 2004), or by potentiating endogenous antimicrobials, most likely via inhibition of major facilitator superfamily drug efflux pumps (Flythe et al., 2013; Harlow et al., 2017b).

Verdrengh et al. (2003) reported that genistein concentrations of 1 and $10 \mu M$ did not inhibit bacterial growth, whereas $370 \mu M$ induced cell death and cell lysis in eukaryotic cells. According to Verdrengh et al. (2004), maximal inhibition of genistein at 50 and $100 \mu M$ was obtained with an incubation time of 10 $\mathrm{h}$, whereas no significant effect of genistein on bacterial viability was observed after $15 \mathrm{~h}$ of incubation. Verdrengh et al. (2004) suggested that the decline in inhibitory effects could be caused by the degradation of genistein in the culture or outgrowth of resistant bacteria. This is in accordance with our results, as we observed delayed and reduced equol production in the experiments using extract amounts that corresponded to genistein concentrations $>45 \mu M$. However, the measured concentrations did not exceed $9 \mu M$, likely corresponding to the solubility of genistein in the rumen fluid.

Although the above-mentioned studies proved the inhibitory effect of genistein on various bacteria, including methicillin-resistant strains of Staphylococcus aureus, daidzein is often used experimentally as the inactive form of genistein because it lacks the $-\mathrm{OH}$ group at position 5 and does not inhibit protein tyrosine kinases (Verdrengh et al., 2004). According to Elghali et al. (2012) and Raimondi et al. (2009), the presence of daidzin and daidzein in the medium has no effect on growth of 22 strains of Bifidobacterium in vitro. Yao et al. (2004) found that daidzein did not affect composition of the Lactobacillus community in the piglet gut, but significantly enriched some Lactobacillus species; they suggested that daidzein might have the potential for use as a prebiotic substance in animal feed. During in vitro studies with goat rumen fluid, Zhu et al. (2002) studied the effect of daidzein on production of VFA and microbial protein and found no significant differences between the treated and control incubations, except for 
incubations with $10 \mu \mathrm{g} / \mathrm{mL}$ daidzein, which resulted in decreased ammonia concentrations and changes in molar proportions of acetate and propionate after $24 \mathrm{~h}$ of incubation. On the other hand, in our previous in vivo study (Kašparovská et al., 2016b), decreases in total and individual VFA were observed when $40 \%$ soybean extract was added to the diet of lactating cows. In the incubations described in the current study, the measurable daidzein concentration did not exceed $10 \mu \mathrm{g} / \mathrm{mL}$. However, the amount of daidzein added corresponded to $349.4 \mu \mathrm{g} / \mathrm{mL}$ of the reaction.

The course of isoflavone metabolism under the abovedescribed in vitro conditions could also be influenced by the lack of adaptation of rumen microbes - the metabolism of isoflavones improves over time and would be more efficient after adaptation of the rumen microflora that normally lasts 6 to 10 d (Shutt et al., 1970; Shutt, 1976). Differences in rumen microbiome profile in cows adapted to dietary isoflavones were described in our previous in vivo study (Kašparovská et al., 2016b), in which changes in bacteria belonging to the phyla Bacteroidetes, Proteobacteria, Firmicutes, and Planctomycetes were noted.

Furthermore, according to Bodas et al. (2012), effects of chemicals added to reactions are more evident in in vitro studies, most likely because the chemical is more uniformly distributed in a batch and the microbes are more quickly exposed to its activity compared with in vivo conditions.

\section{CONCLUSIONS}

The aim of this study was to determine the effect of the type of diet (i.e., hay or concentrate-rich diet) and the concentration of dietary isoflavones on their metabolism in the rumen using in vitro methods. We found no significant differences in glycitein degradation between diet conditions. In contrast, daidzein and genistein were degraded more rapidly in incubations based on the concentrate-rich diet; the concentrations of daidzein and genistein were significantly lower after 6 and $12 \mathrm{~h}$ compared with those in incubations based on the hay diet. Generally, equol production was greater in incubations based on the hay diet. However, higher amounts of added soybean extract (50 or $75 \mathrm{mg}$ ) led to decreased equol production, probably due to inhibitory effects of genistein against gram-positive equolproducing ruminal bacteria.

\section{ACKNOWLEDGMENTS}

This work was supported by the Czech Science Foundation (GACR) project no. 13-34134S.

\section{REFERENCES}

Bernard, F. X., S. Sable, B. Cameron, J. Provost, J. F. Desnottes, J. Crouzet, and F. Blanche. 1997. Glycosylated flavones as selective inhibitors of topoisomerase IV. Antimicrob. Agents Chemother. 41:992-998.

Blaut, M., L. Schoefer, and A. Braune. 2003. Transformation of flavonoids by intestinal microorganisms. Int. J. Vitam. Nutr. Res. 73:79-87.

Bodas, R., N. Prieto, R. García-González, S. Andrés, F. J. Giráldez, and S. López. 2012. Manipulation of rumen fermentation and methane production with plant secondary metabolites. Anim. Feed Sci. Technol. 176:78-93.

Chan, S. G., P. A. Murphy, S. C. Ho, N. Kreiger, G. Darlington, E. K. F. So, and P. Y. Y. Chong. 2009. Isoflavonoid content of Hong Kong soy foods. J. Agric. Food Chem. 57:5386-5390.

Chouinard, P. Y., J. Levesque, V. Girard, and G. J. Brisson. 1997. Dietary soybeans extruded at different temperatures: milk composition and in situ fatty acid reactions. J. Dairy Sci. 80:2913-2924.

Counotte, G. H. M., and R. A. Prins. 1981. Regulation of lactate metabolism in the rumen. Vet. Res. Commun. 5:101-115.

Day, J. K., A. M. Bauer, C. desBordes, Y. Zhuang, B. E. Kim, L. G. Newton, V. Nehra, K. M. Forsee, R. S. MacDonald, C. BeschWilliford, T. H. M. Huang, and D. B. Lubahn. 2002. Genistein alters methylation patterns in mice. J. Nutr. 132:2419S-2423S.

Deng, Y., Y. Pang, Y. Guo, Y. Ren, F. Wang, X. Liao, and B. Yang. 2016. Host-guest inclusion systems of daidzein with 2 -hydroxypropyl- $\beta$-cyclodextrin (HP- $\beta$-CD) and sulfobutyl ether$\beta$-cyclodextrin (SBE- $\beta-\mathrm{CD}$ ): Preparation, binding behaviors and water solubility. J. Mol. Struct. 1118:307-315.

Deng, Y., L.-N. Su, Y. Pang, Y. Guo, F. Wang, X. Liao, and B. Yang. 2017. Preparation, characterization and water solubility of inclusion complexes of daidzein with amino-modified $\beta$-cyclodextrins. Chin. J. Anal. Chem. 45:648-653.

Dickinson, J. M., G. R. Smith, R. D. Randel, and I. J. Pemberton 1988. In vitro metabolism of formononetin and biochanin $\mathrm{A}$ in bovine rumen fluid. J. Anim. Sci. 66:1969-1973.

Edwards, J. E., N. R. McEwan, A. J. Travis, and R. J. Wallace. 2004. $16 \mathrm{~S}$ rDNA library-based analysis of ruminal bacterial diversity Antonie Van Leeuwenhoek 86:263-281.

Elghali, S., S. Mustafa, M. Amid, M. Y. Manap, A. Ismail, and F. Abas. 2012. Bioconversion of daidzein to equol by Bifidobacterium breve 15700 and Bifidobacterium longum BB536. J. Funct. Foods $4: 736-745$

Flythe, M., and I. Kagan. 2010. Antimicrobial effect of red clover (Trifolium pratense) phenolic extract on the ruminal hyper ammonia-producing bacterium, Clostridium sticklandii. Curr. Microbiol. 61:125-131.

Flythe, M. D. B. Harrison, I. A. Kagan, J. L. Klotz, G. L. Gellin, B. M. Goff, and G. E. Aiken. 2013. Antimicrobial activity of red clover (Trifolium pratense L.) extract on caprine hyper ammoniaproducing bacteria. Agric. Food Anal. Bacteriol. 3:176-185.

Gagnon, N., C. Côrtes, D. da Silva, R. Kazama, G. dos Santos, L. Zeoula, C. Benchaar, and H. V. Petit. 2009. Ruminal metabolism of flaxseed (Linum usitatissimum) lignans to the mammalian lignan enterolactone and its concentration in ruminal fluid, plasma, urine, and milk of dairy cows. Br. J. Nutr. 102:1015-1023. https:// doi.org/10.1017/S0007114509344104.

Gardana, C., E. Canzi, and P. Simonetti. 2009. The role of diet in the metabolism of daidzein by human faecal microbiota sampled from Italian volunteers. J. Nutr. Biochem. 20:940-947. https://doi.org/ 10.1016/j.jnutbio.2008.08.006.

Gaya, P., A. Peirotén, M. Medina, and J. M. Landete. 2016. Isoflavone metabolism by a collection of lactic acid bacteria and bifidobacteria with biotechnological interest. Int. J. Food Sci. Nutr. 67:117124. https://doi.org/10.3109/09637486.2016.1144724.

Harlow, B. E., M. D. Flythe, and G. E. Aiken. 2017b. Effect of biochanin A on corn grain (Zea mays) fermentation by bovine rumen amylolytic bacteria. J. Appl. Microbiol. 122:870-880.

Harlow, B. E., M. D. Flythe, I. A. Kagan, and G. E. Aiken. 2017a. Biochanin A (an isoflavone produced by red clover) promotes weight 
gain of steers grazed in mixed grass pastures and fed dried-distillers. Grains Crop Sci. 57:506-514.

Heisig, P. 2001. Inhibitors of bacterial topoisomerases: Mechanisms of action and resistance and clinical aspects. Planta Med. 67:3-12.

Hummelova, J., J. Rondevaldova, A. Balstikova, O. Lapcik, and L. Kokoska. 2015. The relationship between structure in vitro antibacterial activity of selected isoflavones and their metabolites with special focus on antistaphylococcal effect of demethyltexatin. Lett. Appl. Microbiol. 60:242-247.

Hungate, R. E. 1966. The Rumen and Its Microbes. Academic Press, New York, NY.

Hur, H. G., R. D. Bereger, T. M. Heinze, J. O. Lay, J. P. Freeman, J. Dore, and F. Rafii. 2002. Isolation of an anaerobic intestinal bacterium capable of cleaving the $\mathrm{C}$-ring of the isoflavonoid daidzein. Arch. Microbiol. 178:8-12.

Hur, H. G., J. O. Lay, R. D. Beger, J. P. Freeman, and F. Rafii. 2000. Isolation of human intestinal bacteria metabolizing the natural isoflavone glycosides daidzin and genistin. Arch. Microbiol. 174:422-428.

Kasparovska, J., L. Krizova, J. Lochman, K. Dadakova, and T. Kasparovsky. 2016a. Soybean-derived isoflavone determination in rumen fluid and milk by LC-MS-(TOF). J. Chromatogr. Sci. 54:997-1003.

Kašparovská, J., M. Pečínková, K. Dadáková, L. Křǐžová, S. Hadrová, M. Lexa, J. Lochman, and T. Kašparovský. 2016b. Effects of isoflavone-enriched feed on the rumen microbiota in dairy cows. PLoS One 11:e0154642. https://doi.org/10.1371/journal.pone.0154642.

Kong, Y., R. Teather, and R. Forster. 2010. Composition, spatial distribution, and diversity of the bacterial communities in the rumen of cows fed different forages. FEMS Microbiol. Ecol. 74:612-622.

Kostelac, D., G. Rechkemmer, and K. Briviba. 2003. Phytoestrogens modulate binding response of estrogen receptors $\alpha$ and $\beta$ to the estrogen response element. J. Agric. Food Chem. 51:7632-7635.

Kulling, S. E., and M. Metzler. 1997. Induction of micronuclei, DNA strand breaks and HPRT mutations in cultured Chinese hamsterV79 cells by the phytoestrogen coumoestrol. Food Chem. Toxicol. 35:605-613.

Lampe, J. W., S. Karr, A. Hutchins, and J. L. Slavin. 1998. Urinary equol excretion with a soy challenge: Influence of habitual diet. Proc. Soc. Exp. Biol. Med. 217:335-339.

Lipovac, M., A. Pfitscher, S. Hobiger, T. Laschitz, M. Imhof, P. Chedraui, and A. Jungbauer. 2015. Red clover isoflavone metabolite bioavailability is decreased after fructooligosaccharide supplementation. Fitoterapia 105:93-101.

Lund, T. D., D. J. Munson, M. E. Haldy, K. D. R. Setchell, E. D. Lephart, and R. J. Handa. 2004. The phytoestrogen equol acts as an anti-androgen to inhibit prostate growth and hormone feedback. Biol. Reprod. 70:1188-1195.

Lundh, T. 1995. Metabolism of estrogenic isoflavones in domestic animals. Proc. Soc. Exp. Biol. Med. 208:33-39.

Lundh, T. J.-O., H. Petterson, and K. A. Marinsson. 1990. Comparative levels of free and conjugated plant estrogens in blood plasma and cattle fed estrogenic silage. J. Agric. Food Chem. 38:15301534 .

Mao, S. Y., W. Y. Zhu, Q. J. Wang, and W. Yao. 2007. Effect of daidzein on in vitro fermentation by microorganisms from the goat rumen. Anim. Feed Sci. Technol. 136:154-163.

Morris, E., L. E. Olmstead, A. E. Howard-Carroll, G. R. Dickens, M. L. Goltz, C. Courtney-Shapiro, and P. Fanti. 1999. In vitro and in vivo effects of genistein on murine alveolar macrophage TNF alpha production. Inflammation 23:231-239.

Mukne, A. P., V. Viswanathan, and A. G. Phadatare. 2011. Structure pre-requisites for isoflavones as effective antibacterial agents. Pharmacogn. Rev. 5:13-18.

Nan, G. J., J. Shi, Y. R. Huang, J. Sun, J. H. Lv, G. D. Yang, and Y. P. Li. 2014. Dissociation constants and solubilities of daidzein and genistein in different solvents. J. Chem. Eng. Data 59:1304-1311.

Nielsen, I. L. F., and G. Williamson. 2007. Review of the factors affecting bioavailability of soy isoflavones in humans. Nutr. Cancer $57: 1-10$.
Njåstad, K. M., S. A. Adler, J. Hanse-Møller, E. Thuen, A.-M. Gustavsson, and H. Steinshamn. 2014. Gastrointestinal metabolism of phytoestrogens in lactating dairy cows fed silages with different botanical composition. J. Dairy Sci. 97:7735-7750.

Ohta, A., M. Uehara, K. Sakai, M. Takasaki, H. Adlercreutz, T. Morohashi, and Y. Ishimi. 2002. A combination of dietary fructooligosaccharides and isoflavone conjugates increases femoral bone mineral density and equol production in ovariectomized mice. J. Nutr. 132:2048-2054.

Park, M. H., J.-W. Ju, M.-J. Park, and J.-S. Han. 2013. Daidzein inhibits carbohydrate digestive enzymes in vitro and alleviates postprandial hyperglycemia in diabetic mice. Eur. J. Pharmacol. 712:48-52.

Petit, H. V., C. Côrtes, D. da Silva, R. Kazama, N. Gagnon, C. Benchaar, G. T. dos Santos, and L. M. Zeoula. 2009. The interaction of monensin and flaxseed hulls on ruminal and milk concentration of the mammalian lignan enterolactone in late-lactating dairy cows. J. Dairy Res. 76:475-482.

Rafii, F., J. B. Sutherland, B. M. Bridges, M. Park, and M. R. Adams. 2012. Relationship of dietary soy protein to daidzein metabolism by cultures of intestinal microfloras from monkeys. Food Nutr. Sci. $3: 267-273$.

Raimondi, S., L. Roncaglia, M. De Lucia, A. Amaretti, A. Leonardi, and U. M. Pagnoni. 2009. Bioconversion of soy isoflavones daidzin and daidzein by Bifidobacterium strains. Appl. Microbiol. Biotechnol. 81:943-950.

Rowland, I. R., H. Wiseman, T. A. Sanders, H. Adlercreutz, and E. A. Bowey. 2000. Interindividual variation in metabolism of soy isoflavones and lignans: Influence of habitual diet on equol production by the gut microflora. Nutr. Cancer 36:27-32.

Schoefer, L., R. Mohan, A. Braune, M. Birringer, and M. Blaut. 2002. Anaerobic C-ring cleavage of genistein and daidzein by Eubacterium ramulus. FEMS Microbiol. Lett. 208:197-202.

Setchell, K. D. R., N. M. Brown, and E. Lydeking-Olsen. 2002. The clinical importance of the metabolite equol-A clue to the effectiveness of soy and its isoflavones. J. Nutr. 132:3577-3584.

Shutt, D., R. Weston, and J. Hogan. 1970. Quantitative aspects of phytooestrogen metabolism in sheep fed on subterranean clover (Trifolium subterraneum cultivar Clare) or red clover (Trifolium pratense). Aust. J. Agric. Res. 21:713-722.

Shutt, D. A. 1976. The effects of plant oestrogens on animal reproduction. Endeavour 35:110-113.

Stancanelli, R., A. Mazzaglia, S. Tommasini, M. L. Calabrò, V. Villari, M. Guardo, P. Ficarra, and R. Ficarra. 2007. The enhancement of isoflavones water solubility by complexation with modified cyclodextrins: A spectroscopic investigation with implications in the pharmaceutical analysis. J. Pharm. Biomed. Anal. 44:980-984.

Stewart, C. S., and M. P. Bryant. 1988. The rumen bacteria. Pages 21-76 in The Rumen Microbial Ecosystem. P. N. Hobson, ed. Elsevier Applied Science, London, UK.

Tajima, K., R. I. Aminov, T. Nagamine, H. Matsui, M. Nakamura, and Y. Benno. 2001. Diet-dependent shifts in the bacterial population of the rumen revealed with real-time PCR. Appl. Environ. Microbiol. 67:2766-2774.

Tajima, K., S. Arai, K. Ogata, T. Nagamine, H. Matsui, M. Nakamura, R. I. Aminov, and Y. Benno. 2000. Rumen bacterial community transition during adaptation to high-grain diet. Anaerobe 6:273-284.

Tsangalis, D., J. F. Ashton, A. E. J. McGill, and N. P. Shah. 2002. Enzymic transformation of isoflavone phytoestrogens in soymilk by beta-glucosidase-producing bifidobacteria. J. Food Sci. 67:31043113.

Turner, R., T. Baron, S. Wolffram, A. M. Minihane, A. Cassidy, G. Rimbach, and P. D. Weinberg. 2004. Effect of circulating forms of soy isoflavones on the oxidation of low density lipoprotein. Free Radic. Res. 38:209-216.

Verdrengh, M., L. V. Collins, P. Bergin, and A. Tarkowski. 2004. Phytoestrogen genistein as an anti-staphylococcal agent. Microbes Infect. 6:86-92. 
Verdrengh, M., I.-M. Jonsson, R. Holmdahl, and A. Tarkowski. 2003. Genistein as an anti-inflammatory agent. Inflamm. Res. 52:341346.

Wang, X. L., K. H. Shin, H. G. Hur, and S. I. Kim. 2005. Enhanced biosynthesis of dihydrodaidzein and dihydrogenistein by a newly isolated bovine rumen anaerobic bacterium. J. Biotechnol. 115:261-269.

Wocławek-Potocka, I., C. Mannelli, D. Boruszewska, I. KowalczykZieba, T. Waśniewski, and D. J. Skarżyński. 2013. Diverse effects of phytoestrogens on the reproductive performance: cow as a model. Int. J. Endocrinol. 2013:650984. https://doi.org/10.1155/2013/ 650984 .

Xu, J., and K. Q. Luo. 2014. Enhancing the solubility and bioavailability of isoflavone by particle size reduction using a supercritical carbon dioxide-based precipitation process. Chem. Eng. Res. Des. $92: 2542-2549$
Yao, W., W. Y. Zhu, Z. K. Han, B. Williams, S. Tamminga, and A. D. L. Akkermans. 2004. Daidzein increased the density but not composition of Lactobacillus community in piglet digesta during in vitro fermentation as revealed by DGGE and dilution PCR Reprod. Nutr. Dev. 44(Suppl.):S17.

Yuan, J.-P., J.-H. Wang, and X. Liu. 2007. Metabolism of dietary soy isoflavones to equol by human intestinal microflora-Implications for health. Mol. Nutr. Food Res. 51:765-781.

Zhengkang, H., G. Wang, W. Yao, and W. Y. Zhu. 2006. Isoflavonic phytoestrogens-New prebiotics for farm animals: A review on research in China. Curr. Issues Intest. Microbiol. 7:53-60.

Zhu, W. Y., S. Y. Mao, Q. J. Wang, W. Yao, Q. Liu, and M. K. Theodorou. 2002. Effects of daidzein on in vitro fermentation of micro-organisms from the goat rumen. Reprod. Nutr. Dev. 42(Suppl.):S71 